\title{
Association Between Gastrointestinal Bleeding With Clinical Outcome On Acute Ischemic Stroke Patient
}

Lisda Amalia ( $\square$ dr.lisda@gmail.com )

Universitas Padjadjaran https://orcid.org/0000-0001-5676-0787

Rico Defryantho

Universitas Padjadjaran

Ida Parwati

Universitas Padjadjaran

Ahmad Rizal Ganiem

Universitas Padjadjaran

Ramdan Panigoro

Universitas Padjadjaran

\section{Research article}

Keywords: Acute ischemic stroke, gastrointestinal bleeding, mortality, length of stay.

Posted Date: August 22nd, 2019

DOI: https://doi.org/10.21203/rs.2.13399/v1

License: (c) (i) This work is licensed under a Creative Commons Attribution 4.0 International License.

Read Full License 


\section{Abstract}

Background Gastrointestinal bleedingis one of the complication of acute ischemic stroke and cause of increased mortality and length of stay. This is caused by a delay in the administration of antiplatelet or anticoagulant.Objective.To find the association between gastrointestinal bleeding with clinical outcome in acute ischemic stroke patient.Methods. This study was a prospective observational, conducted at Hasan Sadikin Hospital Bandung for 4 months (November 2017-February 2018). Acute ischemic stroke patients that fulfill the inclusion and exclusion were observed while being inpatients to observe their mortality and length of stay.This study used univariat, bivariat, multivariat, and stratification analysis.Results. A total of 100 acute ischemic stroke patients were found, and 24 patients had gastrointestinal bleeding. A history of previous peptic ulcer/gastrointestinal bleeding was found most often in patient with gastrointestinal bleeding $(20.8 \% / p=0.003)$.Median NIHSS score is higher ( $16 \mathrm{vs}$ $7 / p<0.001)$ and GCS score was lower (12 vs 15/p<0.001) in patients with gastrointestinal bleeding. Multivariate analysis showed that gastrointestinal bleeding were significantly associated with survival ( $p$ $=0.021)$ and length of stay $(p=0.008)$. The analysis of stratification showed subjects with infections who later experienced gastrointestinal bleeding had a lower risk of death and length of stay than subjects without infection who experienced gastrointestinal bleeding (1.7 vs 22.5 times and 1.5 vs 2 times).Conclusion.Gastrointestinal bleeding had more increased mortality and length of stay than without gastrointestinal bleeding in acute ischemic stroke patient.

\section{Background}

According to data from the World Health Organization (WHO) in 2015, stroke is the number two cause of death in the world after ischemic heart disease. Data from the Health Research and Development Agency of the Indonesian Ministry of Health based on a 2014 survey, strokes occupy the top position of causes of death in Indonesia. Estimated burden of disease (disability, number of sufferers, and death) caused by stroke will increase every year. ${ }^{1-3}$

Ischemic stroke is the most common type of stroke, reaching $80 \%$ of all stroke events in the world. Outcomes in acute ischemic stroke are affected, among others, by complications that occur, both neurological and non-neurological. There are various non-neurological complications that can occur in patients with acute ischemic stroke, including gastrointestinal bleeding and infection. Gastrointestinal bleeding in patients with acute ischemic stroke is generally in the form of upper gastrointestinal bleeding. Infections that occur in acute ischemic stroke generally are pneumonia and urinary tract infections.

Gastrointestinal bleeding has been reported since $1800 .^{5}$ In patients with haemorrhagic stroke, gastrointestinal bleeding occurs in about $26.7 \%$, the incidence is related to age and volume of bleeding. ${ }^{6}$ The incidence of gastrointestinal bleeding in ischemic stroke patients is lower, ie $0.1-8 \%$. The report on the incidence of gastrointestinal bleeding in ischemic stroke in Asia ranges from $1.4-7.8 \% .7,8$

Gastrointestinal bleeding is still a serious problem in both stroke and ischemic stroke. Pathophysiologically, there are different mechanisms for the occurrence of gastrointestinal bleeding in both types of stroke. Gastrointestinal bleeding in bleeding strokes occurs due to suppression of the 
pituitary gland by a hematoma. This causes an increase in cortisol resulting in the release of stomach acid. Gastrointestinal bleeding in ischemic stroke is caused more by the neuroinflamasi process that occurs after ischemic in the brain then stimulates vagal hyperactivity resulting in an increase in stomach acid. In addition to gastrointestinal bleeding, infection is a non-neurological complication that is often found. The incidence of infection is around $23 \%-50 \%$ in patients with acute ischemic stroke. Extensive ischemic stroke causes an increase in catecholamines through the sympathetic system. The increase in catecholamines causes suppression of the immune system through neutrophil malfunction, making it easier to get infected.

The incidence of gastrointestinal bleeding and infection in acute ischemic stroke patients is associated with poor outcomes. The output includes increased disability after stroke, death, and prolonging hospital care. One of the factors that influence the outcome is the cessation of antiplatelet or anticoagulant therapy which can cause a thrombotic state that can aggravate brain ischemic conditions. The results of this study are expected to provide clinical consideration for the provision of prophylactic treatment for gastrointestinal bleeding in patients with acute ischemic stroke.

\section{Methods}

This was a prospective observational study conducted in neurology ward Dr. Hasan Sadikin Bandung from November 2017 to February 2018. Subjects for the study of acute ischemic stroke were treated in the neurology ward and fulfilled the inclusion and exclusion criteria. The inclusion criteria were patients with acute ischemic stroke diagnosis based on clinical and brain imaging. We classified the patient using Oxfordshire Community Stroke Project Subtype (OCSP) Classification : Lacunar infarct(LACI), Partial Anterior Circulation Infarct (PACl), Total Anterior Circulation Infarct (TACl), Posterior Occlusion Circulation Infarc (POCl).

The exclusion criteria were gastrointestinal bleeding before treatment at Hasan Sadikin Hospital. Data analysis used was univariate, bivariate, multivariate, and statistical stratification data analysis.

\section{Results}

A total of 100 acute ischemic stroke patients who met the inclusion and exclusion criteria. During treatment, the subjects were observed until they were discharged from the hospital or died, then the length of time the subject was treated. The characteristics of the research subject can be seen in Table 1. Table 1 shows the mean age of subjects with older gastrointestinal bleeding compared with no gastrointestinal bleeding (61 \pm 13 vs $58 \pm 10$ years). Hypertension is the most risk factor in all subjects (87.5\% vs $85.5 \%)$. Embolic type strokes are more common in subjects with gastrointestinal bleeding, which is $66.7 \%$. In contrast, the type of atherothrombosis was more common in subjects without bleeding, which was $57.9 \%$. This was statistically significant $(p=0.036)$.

Other characteristics that differed significantly in the two groups were atrial fibrillation ( $25 \%$ vs $5.2 \%$; $p$ $=0.012)$, history of peptic ulcer or previous gastrointestinal bleeding ( $20.8 \%$ vs $0 ; p=0.003)$, history of penuse of antiplatelet or anticoagulant before hospital admission ( $29.2 \%$ vs $11.8 \% ; p=0.044)$, NIHSS 
score (16 vs 7; $p=<0.001)$, GCS (12 vs $15 ; p=<0.001)$, and AIS-GIB (6 vs $3 ; p=<0.001$ ).

In addition, this study looks at the characteristics of subjects with infections as confounding variables. The number of subjects with infection in this study were 27 subjects. The average age of subjects with infection is 61 years with more women than men (17 vs 10). Subjects with more infections in embolic type strokes than atherothrombotic types (18 vs 9). Median GCS and NIHSS scores respectively 12 and 17.

\section{Relationship to Survival of Gastrointestinal Bleeding}

Table 2 shows that of the 24 subjects with gastrointestinal bleeding half died, while without bleeding only $7.9 \%$. This is significantly different $(p<0.001)$. In addition, subjects with bleeding died within a median time of 3 days (Quartile Range interval / IQR: 2-7) and most of the causes of death were neurological causes in this case cerebral herniation (8 subjects / 66\%). Meanwhile, subjects without bleeding died within a median of 8 days (IQR 3-10) and fewer died of neurological causes (2 subjects / 33\%).

Of the 27 patients diagnosed with infection during treatment, almost half died, while without infection only $6.8 \%$. This is significantly different $(p<0.001)$. Infection in this study was pneumonia and urinary tract infections. In addition, it was found that subjects with infections died within a median of 8 days (IQR: 3-10) and fewer died of neurological causes (6 subjects / 46\%; meanwhile subjects without infection died within a median of 3 days (IQR 2-3) and most died of neurological causes (4 subjects / $80 \%)$.

Based on bivariate analysis, subjects with gastrointestinal bleeding were 6.3 times more likely to die than without bleeding. Then multivariate analysis showed that subjects with gastrointestinal bleeding had a risk of dying 3.2 times greater than without bleeding after being controlled by confounding infection variables $(p=0.021)$ (Table 3 ).

Table 3 shows that there were 13 subjects with infections who had gastrointestinal bleeding more than half (8 subjects) died, while those who did not bleed only 5 subjects (38.5\%). Uninfected subjects who experienced gastrointestinal bleeding as many as 4 subjects $(36.4 \%)$ died, while those who did not bleed only 1 subject $(1.6 \%)$.

Subjects with infections then experiencing gastrointestinal bleeding have a risk of dying of 1.7 times. Whereas subjects without infection then experienced gastrointestinal bleeding at a risk of death of 22.5 times.

\section{Relationship to Gastrointestinal Bleeding with Length of Stay}

Table 4 shows that in the group of living subjects the length of stay $>7$ days was greater in gastrointestinal bleeding than without bleeding ( $75 \%$ vs $32.9 \%)$. This is significantly different $(p=0.009)$. Living subjects who were diagnosed with infection had more than 7 days of treatment compared to those without infection $(78.6 \%$ vs $30.9 \%)$. This is significantly different $(p<0.001)$. From these results it was found that subjects with gastrointestinal bleeding were 2.3 times more likely to be treated for 7 days than without bleeding.

After multivariate analysis, it was found that subjects living with gastrointestinal bleeding had a risk of length of stay of $>7$ days, 1.8 times rather than without bleeding after being controlled by confounding 
infection variables $(p=0.008)$ (Table 4).

Table 5 shows all subjects with gastrointestinal bleeding died ( 5 subjects / 100\%), while those who did not bleed 6 subjects $(66.7 \%)$. Uninfected subjects who experienced gastrointestinal bleeding as many as 4 subjects (57.1\%) died, while those who did not bleed 17 subjects $(27.9 \%)$.

Subjects with infection then experiencing gastrointestinal bleeding have a risk of dying that is 1.5 times. Whereas subjects without infection then experienced gastrointestinal bleeding at risk of dying twice.

\section{Discussion}

\section{Characteristics of Research Subjects}

The incidence of gastrointestinal bleeding in this study was $24 \%$. This incidence is higher than other studies in the world, including the United States (1.2\%), Japan (1.4\%), Canada (1.5\%), China (1.5\%), Malaysia (5.2\%), Philippines (7\%) and Taiwan (7.8\%). Research in Taiwan says Asian races have more bleeding than Caucasians associated with Helicobacter pylori infection. Research in Indonesia, Taiwan, the Philippines, and Malaysia was only in one hospital, while in the United States, Japan, Canada, and China multicentre studies so that there were differences in the number of subjects. In addition, this difference may be due to differences in the operational definition of gastrointestine bleeding I. In developed countries, endoscopic examination is the gold standard for the diagnosis of gastrointetinal bleeding, whereas in this study only based on clinical findings. $7,11,12$

This study showed the proportion of women who experienced gastrointestinal bleeding was slightly more than men (54.2\% vs $45.8 \%)$, but no significant difference was found. Conversely there was a significant difference in China and Taiwan where men were more at risk of developing gastrointestinal bleeding. This might be due to differences in the characteristics and number of research subjects. ${ }^{10,12}$ The average age of the study subjects was younger (58 years) compared to the stroke register in Indonesia (65 years), Chinese (66 years), Taiwan (69 years). This might be due to differences in the characteristics and number of research subjects. Another reason is that Indonesia is a developing country that experiences unhealthy lifestyle changes that increases risk factors for stroke such as hypertension and diabetes mellitus. The age of subjects with gastrointestinal bleeding was older compared to those without gastrointetinal bleeding (61 vs 58 years) according to the study in Taiwan (74 vs 69 years), Japanese (76 vs 73 years), Canada (75 vs 72 years). This is because at an older age the physiological function of the gastrointestinal system decreases. This causes a decrease in the function of protective cells in the gastrointestinal system so that bleeding occurs more easily. $7,13,14$

This study showed the risk factors for dyslipidemia were slightly lower in subjects with gastrointestinal bleeding (54.1\%) compared to those without gastrointestinal bleeding (60.5\%). This is consistent with previous studies in Japan ( $29.2 \%$ vs $49.6 \%$ ), Canada (18\% vs $34 \%$ ). The cause of this event is not yet fully known, but previous studies say it might be due to the use of antibiotics for eradicating bacteria, especially Helicobacter pylori. Such eradication may be related to an increase in serum cholesterol or triglycerides.

Subjects with gastrointestinal bleeding had atrial fibrillation risk factors and embolic stroke type than 
those without gastrointestinal bleeding ( $25 \%$ vs $5.2 \%$ and $66.7 \%$ vs. $42.1 \%)$. This is because in embolic strokes there is a widespread brain ischemic so that the neuroinflammation in the brain gets more intense. The inflammatory mediator involves activating the cervico-vagal nerve pathway which will activate parasympathetic pathway to produce acetylcholine vagal hyperactivity. This vagal hyperactivity stimulates production of acid chloride in gastric causing gastrointestinal bleeding. Previous research in Japan (36\%) and Canada (20\%) showed the same cases.

Subjects with gastrointestinal bleeding had a history of peptic ulcer / gastrointestinal bleeding and the use of antiplatelet / anticoagulant therapy before admission was slightly more than without gastrointestinal bleeding (20.8\% vs 0 and $29.2 \%$ vs. $11.8 \%)$. These results are in line with previous studies in Taiwan, Japan, the United States, and Canada. This is because the use of antiplatelet is associated with damage to the gastric epithelium directly and inhibits the production of prostaglandin by the gastric mucosa, causing gastric ulcers. The use of anticoagulants is related to the systemic effects caused by inhibition of clotting factors involving vitamin K. ${ }^{11,15,16}$

Subjects with gastrointestinal bleeding had a higher NIHSS score at admission compared to those without gastrointestinal bleeding (16 vs 7). The results of this study are in accordance with other studies in Japan. GCS scores at admission are lower in subjects with gastrointestinal bleeding (12) compared to those without gastrointestinal bleeding (15). This is related to the severity of the ischemic stroke that occurs. The median mRS score before admission did not differ between subjects with bleeding and without bleeding. This is caused by the severity of the stroke that occurred before is relatively mild.

Subjects with gastrointestinal bleeding had more infections than without bleeding (54.2\% vs $18.4 \%)$. Research in Taiwan (79.2\% vs. $19.1 \%$ ) and the United States (5.2\% vs $1 \%$ ) showed similar results. Gastrointestinal bleeding causes infection to be under debate. There are several hypotheses which state that the severity of ischemic stroke causes gastrointestinal bleeding. Nosocomial infections that occur due to disability in the stroke. Another opinion said the infection caused gastrointestinal bleeding due to changes in faktor coagulation due to inflammation that occurs. ${ }^{11,17}$

\section{Relationship to Gastrointestinal Bleeding with Survival}

This study showed gastrointestinal bleeding significantly affected the incidence of death in acute ischemic stroke patients $(p=0.021)$. The risk of death is 3.2 times greater in gastrointestinal bleeding than without bleeding. The results of this analysis have been controlled by confounding infection variables. Although the risk of death in infection is higher (3.9 times), the focus of this study is gastrointestinal bleeding. Based on these results, gastrointestinal bleeding plays an important role in survival without being influenced by infection.

Infection is considered to be a confounding variable because in several studies in Taiwan, the United States, Brazil and Poland, infection significantly affected mortality in acute ischemic stroke patients. Extensive ischemic stroke causes an increase in catecholamines through the sympathetic system. The increase in catecholamines causes suppression of the immune system through neutrophil malfunction, making it easier to get an infection. $9,11,18$

Research in Japan said the mortality of subjects with gastrointestinal bleeding was higher than 
without bleeding ( $15.7 \%$ vs $1.9 \%$ ) with a risk of death 8.7 times. In Canada, the mortality of subjects with gastrointestinal bleeding was $28 \%$ with a risk of death 1.5 times greater than without bleeding. Research in the United States showed that as many as $16.1 \%$ of subjects with gastrointestinal bleeding died with a risk of death 1.8 times greater than without bleeding. Based on these data, gastrointestinal bleeding significantly affected death in patients with acute ischemic stroke. ${ }^{11}$

Stratification analysis based on the presence or absence of infection diagnosis showed that subjects with infections who subsequently had gastrointestinal bleeding had a lower risk of death than those without infection and then had gastrointestinal bleeding (1.7 times vs. 22.5 times).

In addition there were 10 patients without gastrointestinal bleeding who were given prophylactic therapy (PPI, histamine $\mathrm{H} 2$ antagonist, or cytoprotectic agent), where only 1 subject died due to sepsis.

\section{Relationship to Gastrointestinal Bleeding with Length of Stay}

This study showed subjects with gastrointestinal bleeding were treated more than 7 days (75\%) compared with no gastrointestinal bleeding (32.9\%). The risk of treatment is 1.8 times longer in subjects with gastrointestinal bleeding than without bleeding after being controlled by confounding infection variables. Although the risk of long-term treatment for infection is higher (2.2 times), the focus of this study is gastrointestinal bleeding. Based on these results, gastrointestinal bleeding plays an important role in the length of care without infection. Infection is considered a confounding variable because previous studies in Taiwan, the United States, Denmark, and the United Kingdom mentioned infection affecting the length of stay in acute ischemic stroke patients. ${ }^{11,19}$

The results of this study are in accordance with previous studies in the United States. Research in the United States found that ischemic stroke patients with gastrointestinal bleeding had a longer average length of stay (11 days) than without gastointestinal bleeding (5 days) with a 2.3 times longer risk of treatment. Patient care was longer due to examination and therapy. additions were made to patients with gastrointestinal bleeding such as delaying antiplatelet / anticoagulant initial therapy, blood transfusion, and endoscopy to find gastrointestinal bleeding sources. Based on these data, gastrointestinal bleeding has a significant effect on prolonging the length of treatment in acute ischemic stroke patients $(p=$ 0.008)..$^{11}$

Stratification analysis based on the presence or absence of infection diagnosis showed that subjects with infections who subsequently experienced gastrointestinal bleeding had a long risk of treatment not much different than those without infection and then had gastrointestinal bleeding (1.5 times vs. 2 times).

\section{Research Limitations}

This study used clinical symptoms to diagnose gastrointestinal bleeding from brownish NGT hose, not confirmed by endoscopy to find the source of bleeding and Helicobacter pylori infection. This study did not take into account antiplatelet administration, anticoagulants, or other drugs that might affect the gastrointestinal tract during hospital treatment.

\section{Conclusions}


Acute ischemic stroke that has gastrointestinal bleeding has a higher risk of death and longer treatment duration than without gastrointestinal bleeding. Infection events during treatment affect mortality and length of stay in subjects with acute ischemic stroke. Embolic stroke type, having atrila fibrillation, low GCS scoe, higher NIHSS score, history of peptic ulcer, history of antiplatelet/anticoagulant therapy and infection during hospitalization in acute ischemic stroke patients had tendency towards gastrointestinal bleeding. Prophylactic treatment using PPI, histamine $\mathrm{H} 2$ antagonist, or cytoprotectic agent can reduce mortality in acute ischemic stroke patients.

\section{Abbreviations}

GCS : Glasgow Coma Scale; NIHSS : National Institute of Health Stroke Scale; NGT : Naso Gastric Tube ; PPI : Proton Pump Inhibitors; H2 : Histamine 2; AIS GIB : Acute Ischemic Stroke Gastrointestinal Bleeding ; OCSP : Oxfordshire Community Stroke Project Subtype Classification ; LACI : Lacunar infarct ; PACl : Partial Anterior Circulation Infarct : TACI : Total Anterior Circulation Infarct; POCI : Posterior Occlusion Circulation Infarct.

\section{Declarations}

\section{DECLARATION}

Ethical approval of this study were obtained from Research Ethic Committee of Hasan Sadikin Hospital Bandung. Written informed consent was obtained from all patients for their participation in this study. All data or analysis during this study are provided by the corresponding author in this article supplementary files.

\section{Competing Interest}

There is no competing interest.

\section{Funding}

There is no funding for this research

\section{Ethical Clearance}

This research was granted approveal by the ethical committee Dr. Hasan Sadikin Hospital Bandung, Indonesia (LB.04.01/A05/EC/327/XI/2017). 


\section{Consent for Publication}

This publication is one of the requirements to pursue doctoral title from Faculty of Medicine, University of Padjadjaran Bandung, Indonesia.

\section{Availability of Data and Material}

The full data showed in supplementary material.

\section{Authors' Contribution}

LA: preparation, collecting, analysis, making of manuscript, submission for publication

RD: preparation, collecting, analysis

IP: Analysis

ARG: Analysis

RP: Analysis

All authors have read and approved the manuscript

\section{Acknowledgements}

Not applicable

\section{References}

1. Tempo. Stroke penyebab kematian tertinggi di Indonesia: Koran Tempo; 2015 [Diunduh 15 Mei 2017].Tersedia dari http://koran.tempo.co /konten /2015/05/18/372946/ Stroke-PenyebabKematian- Tertinggi-di- Indonesia.

2. Soertidewi L, Misbach J. Epidemiologi stroke. Dalam: Soertidewi L, Jannis J, editor Stroke: aspek diagnosis, patofisiologi, manajemen Badan Penerbit FKUI. 2011:1-5. 
3. WHO. Top 10 causes of death worlwide 2017 [Diunduh 9 November 2017].Tersedia dari http://www.who.int/ mediacentre/ factsheets/ fs310/en/.

4. World Heart Federation. Stroke [Diunduh 3 Oktober 2017].Tersedia dari https:/ /www.world-heartfederation.org/ resources/ stroke/.

5. Plummer MP, Blaser AR, Deane AM. Stress ulceration: prevalence, pathology, and association with adverse outcomes. Critical Care. 2014;18(213):1-7.

6. Yang TC, Li JG, Shi HM, Yu DM, Shan K, Li LX, et al. Gastrointestinal bleeding after intracerebral hemorrhage: a retrospective review of 808 cases. Am J Med Sci. 2013;346(4):279-82.

7. Ogata T, Kamouchi M, Matsuo R. Gastrointestinal bleeding in acute ischemic stroke: recent trends from the fukuoka stroke registry. Cerebrovasc Dis Extra. 2014;4:156-64.

8. Timbol ABG, De Castillo LLC, Djajakusuma AV, Co VCO, Pasco PMD, Banez VP. Prediction of in hospital gastrointestinal bleeding after acute ischemic stroke using AIS-GIB risk model: a validation Study. Philiiphines. 2016:1-23.

9. Shim $\mathrm{R}$, Wong $\mathrm{CH}$. Ischemia, immunosuppression and infection-tackling the predicaments of poststroke complications. International journal of molecular sciences. 2016;17(1):64.

10. Ji R, Shen H, Pan Y, Wang P, Liu G, Wang Y, et al. Risk score to predict gastrointestinal bleeding after acute ischemic stroke. BMC Gastroenterol. 2014;14:130.

11. Rumalla K, Mittal MK. Gastrointestinal bleeding in acute ischemic stroke: a population-based analysis of hospitalizations in the United States. J Stroke \& Cerebrovasc D 2016;3(44):1-8.

12. Holster IL, Kuipers EJ. Management of acute nonvariceal upper gastrointestinal bleeding: current policies and future perspectives. World journal of gastroenterology: WJG. 2012;18(11):1202.

13. Yudiarto F, Machfoed M, Darwin A, Ong A, Karyana M. Indonesia Stroke Registry (S12. 003). Neurology. 2014;82.

14. Hsu HL, Lin YH, Huang YC, Weng HH, Lee M, Huang WY, et al. Gastrointestinal hemorrhage after acute ischemic stroke and its risk factors in Asians. Eur Neurol. 2009;62(4):212-8.

15. Moukarbel GV, Bhatt DL. Antiplatelet therapy and proton pump inhibition: clinician update. Circulation. 2012;125(2):375-80.

16. Vaduganathan $M, B$ Batt DL. Gastrointestinal bleeding with oral anticoagulation: understanding the scope of the problem. Clinical Gastroenterology and Hepatology. 2017;15(5):691-3.

17. Altemeier W, Fullen W, McDonough J. Sepsis and gastrointestinal bleeding. Annals of surgery. 1972;175(5):759.

18. Machado MF, Brucki SMD, Nogueira CF, Rocha MSG. Infectious disease is the most common cause of death among stroke patients: two-years of follow-up. Arquivos de neuro-psiquiatria. 2013;71(6):371-5.

19. George AJ, Boehme AK, Siegler JE, Monlezun D, Fowler BD, Shaban A, et al. Hospital-acquired infection underlies poor functional outcome in patients with prolonged length of stay. ISRN stroke. 2013;2013. 


\section{Tables}

Table 1. Data of characteristic ischemic stroke patients

\begin{tabular}{|c|c|c|c|c|}
\hline Characteristics & $\begin{array}{c}\text { Total } \\
(\mathrm{n}=100)\end{array}$ & $\begin{array}{l}\text { Gastrointestinal } \\
\text { bleeding }(n=24)\end{array}$ & $\begin{array}{c}\text { Without Gastrointestinal } \\
\text { bleeding }(n=76)\end{array}$ & $p$-value \\
\hline Age, year (mean \pm SD) & - & $61 \pm 13$ & $58 \pm 10$ & 0.235 \\
\hline \multicolumn{5}{|l|}{ Gender, n (\%) } \\
\hline Male & 42 & $11(45.8)$ & $31(40.8)$ & \multirow[t]{2}{*}{0.663} \\
\hline Female & 58 & $13(54.2)$ & $45(59.2)$ & \\
\hline \multicolumn{5}{|l|}{ Risk factors, n (\%) } \\
\hline Hypertension & 86 & $21(87.5)$ & $65(85.5)$ & 1.000 \\
\hline Diabetes melitus & 22 & $5(20.8)$ & $17(22.3)$ & 0.874 \\
\hline Dyslipidemia & 59 & $13(54.1)$ & $46(60.5)$ & 0.581 \\
\hline Hyperuricemia & 29 & $8(33.3)$ & $21(27.6)$ & 0.592 \\
\hline Atrial Fibrilation & 10 & $6(25.0)$ & $4(5.2)$ & $0.012 *$ \\
\hline Previous stroke & 44 & $12(50.0)$ & $32(42.1)$ & 0.497 \\
\hline Smoking & 40 & $10(41.6)$ & $30(39.5)$ & 0.848 \\
\hline
\end{tabular}

Type of ischemic stroke, $\mathrm{n}$

(\%)

\begin{tabular}{|c|c|c|c|c|}
\hline Aterotrombotic & 52 & $8(33.3)$ & $44(57.9)$ & $0.036^{*}$ \\
\hline Embolic & 48 & $16(66.7)$ & $32(42.1)$ & \\
\hline $\begin{array}{l}\text { History of gastrointestinal } \\
\text { bleeding, } \mathrm{n}(\%)\end{array}$ & 5 & $5(20.8)$ & 0 & $0.003 *$ \\
\hline History of cirrhosis hepatis & 0 & 0 & 0 & - \\
\hline $\begin{array}{l}\text { History of antiplatetelet } \\
\text { therapy, n (\%) }\end{array}$ & 16 & $7(29.2)$ & $9(11,8)$ & $0.044 *$ \\
\hline $\begin{array}{l}\text { NIHSS }{ }^{a} \text { on admission, } \\
\text { median (range) }\end{array}$ & - & $16(3-28)$ & $7(2-20)$ & $<0.001 *$ \\
\hline $\begin{array}{l}\mathrm{mRS}^{\mathrm{b}} \text { on admission, median } \\
\text { (range) }\end{array}$ & - & $0(0-4)$ & $0(0-3)$ & 0.258 \\
\hline $\begin{array}{l}\text { GCS }^{\mathrm{C}} \text { admission, median } \\
\text { (rentang) }\end{array}$ & - & $12(5-15)$ & $15(5-15)$ & $<0.001^{*}$ \\
\hline \multicolumn{5}{|l|}{ Subtype OCSP ${ }^{\mathrm{d}}, \mathrm{n}(\%)$} \\
\hline LACI & 20 & $2(8.3)$ & $18(23.7)$ & 0.101 \\
\hline PACI & 57 & $14(58.3)$ & $43(56.6)$ & 0.88 \\
\hline TACI & 15 & $6(25.0)$ & $9(11.8)$ & 0.116 \\
\hline POCI & 8 & $2(8.3)$ & $6(7.9)$ & 1,000 \\
\hline
\end{tabular}

gnificant analysis $\mathrm{p}<0,005)$; ${ }^{\mathrm{a}}$ National Institute of Health Stroke Scale; ${ }^{\mathrm{b}}$ modified Rankin Scale; ${ }^{\mathrm{c}}$ Glasgow Coma ; ${ }^{\mathrm{d}}$ Oxfordshire Community Stroke Project Subtype (OCSP) Classification : Lacunar infarct(LACI), Partial Anterior lation Infarct (PACI), Total Anterior Circulation Infarct (TACI), Posterior Occlusion Circulation Infarc (POCI)

Table 2. Bivariat and multivariate analysis between gastrointestinal bleeding and survival 


\begin{tabular}{|c|c|c|c|c|c|}
\hline \multirow[t]{2}{*}{ Variable } & \multirow[t]{2}{*}{$\mathbf{n}$} & \multicolumn{2}{|c|}{ Survival } & \multirow[b]{2}{*}{$\mathrm{RR}(95 \% \mathrm{CI})$} & \multirow[t]{2}{*}{$p$-value } \\
\hline & & $\begin{array}{l}\text { Dead } \\
\mathrm{n}=18\end{array}$ & $\begin{array}{c}\text { Survive } \\
\mathrm{n}=82\end{array}$ & & \\
\hline \multicolumn{6}{|c|}{ Gastroointestinal bleeding,n(\%) } \\
\hline Yes & 24 & $12(50.0)$ & $12(50.0)$ & $6.3(2.6-15.1)$ & $<0.001^{*}$ \\
\hline No & 76 & $6(7.9)$ & $70(92.1)$ & & \\
\hline \multicolumn{6}{|l|}{ Infection,n(\%) } \\
\hline Yes & 27 & $13(48.1)$ & $14(51.9)$ & $7.0(2.7-17.8)$ & $<0.001 *$ \\
\hline No & 73 & $5(6.8)$ & $68(93.2)$ & & \\
\hline
\end{tabular}

* Signicant statistical analysis

\begin{tabular}{lcc}
\hline \multicolumn{1}{c}{ Variabel } & Adjusted RR (95\% CI) & p-value \\
\hline Gastrointestinal bleeding & $3.2(1.2-8.3)$ & $0.021^{*}$ \\
Infection & $3.9(1.4-11.4)$ & $0.012^{*}$ \\
\hline
\end{tabular}

Dependent variable: outcome (death); * significant statistical anaysis

Table 3. Statification anaylisis: Association gastrointestinal bleeding and infection with survival

\begin{tabular}{|c|c|c|c|c|c|}
\hline \multicolumn{2}{|r|}{ Variable } & \multirow[t]{2}{*}{$\mathbf{n}$} & \multicolumn{2}{|c|}{ Survival } & \multirow[t]{2}{*}{$\mathbf{R} \mathbf{R}$} \\
\hline Infection & Gastrointestinal bleeding & & Dead (\%) & Survive(\%) & \\
\hline \multirow[t]{2}{*}{ Yes } & Yes & 13 & $8(61.5)$ & $5(38.5)$ & \multirow[t]{2}{*}{1.7} \\
\hline & No & 14 & $5(35.7)$ & $9(64.3)$ & \\
\hline \multirow[t]{2}{*}{ No } & Yes & 11 & $4(36.4)$ & 7 (63.6) & \multirow[t]{2}{*}{22.5} \\
\hline & No & 62 & $1(1.6)$ & $61(98.4)$ & \\
\hline
\end{tabular}

Table 4. Bivariat and multivariate analysis: Association gastrointestinal bleeding and length of stay on survival group

\begin{tabular}{|c|c|c|c|c|c|}
\hline \multirow[t]{2}{*}{ Variable } & \multirow[t]{2}{*}{$\mathbf{n}$} & \multicolumn{2}{|c|}{ Length of stay } & \multirow[t]{2}{*}{$\mathrm{RR}(95 \% \mathrm{CI})$} & \multirow[t]{2}{*}{$p$-value } \\
\hline & & $\begin{array}{c}>7 \text { days } \\
\mathrm{n}=32\end{array}$ & $\begin{array}{c}\leq 7 \text { days } \\
n=50\end{array}$ & & \\
\hline \multicolumn{6}{|c|}{ Gastrointestinal bleeding,n(\%) } \\
\hline Yes & 12 & $9(75.0)$ & $3(25.0)$ & $2.3(1.4-3.6)$ & $0.009 *$ \\
\hline No & 70 & $23(32.9)$ & $47(67.1)$ & & \\
\hline \multicolumn{6}{|l|}{ Infection } \\
\hline Yes & 14 & $11(78.6)$ & $3(21.4)$ & $2.5(1.6-3.9)$ & $<0.001 *$ \\
\hline No & 68 & $21(30,9)$ & $47(69,1)$ & & \\
\hline
\end{tabular}

- Significant statistical analysis 


\begin{tabular}{lcc}
\hline \multicolumn{1}{c}{ Variable } & Adjusted RR (95\% CI) & p-value \\
\hline Gastrointestinal bleeding & $1.8(1.2-2.7)$ & $0.008^{*}$ \\
Infection & $2.2(1.4-3.5)$ & $0.001^{*}$ \\
\hline
\end{tabular}

Dependent variable: outcome (length of stay); * significant statistical anaysis

Table 5. Statification anaylisis: Association gastrointestinal bleeding and length of stay on survival group

\begin{tabular}{|c|c|c|c|c|c|}
\hline \multicolumn{2}{|r|}{ Variable } & \multirow[t]{2}{*}{$\mathrm{n}$} & \multicolumn{2}{|c|}{ Length of stay } & \multirow[t]{2}{*}{$\mathrm{RR}$} \\
\hline Infection & Gastrointestinal bleeding & & $\begin{array}{c}>7 \text { days } \\
(\%)\end{array}$ & $\leq 7$ days $(\%)$ & \\
\hline \multirow[t]{2}{*}{ Yes } & Yes & 5 & $5(100)$ & $0(0)$ & \multirow[t]{2}{*}{1.5} \\
\hline & No & 9 & $6(66.7)$ & $3(33.3)$ & \\
\hline \multirow[t]{2}{*}{ No } & Yes & 7 & $4(57.1)$ & $3(42.9)$ & \multirow[t]{2}{*}{2.0} \\
\hline & No & 61 & $17(27.9)$ & $44(72.1)$ & \\
\hline
\end{tabular}

